\title{
Fundraising Capacity of HIV/AIDS Community-Based Organizations in 3 Years (2017-2019) in Ho Chi Minh City, Vietnam
}

\author{
Tran Chi Thanh',2, Pham Duc Trinh ${ }^{3}$, Nguyen Duc Thanh4, Linus Olson ${ }^{5,6}$, Mattias Larsson' \\ ${ }^{1}$ Nguyen Tat Thanh University, HCMC, Vietnam \\ ${ }^{2}$ Dinh Tien Hoang Institute of Medicine, Hanoi, Vietnam \\ ${ }^{3}$ College of Foreign Economic Relation, HCMC, Vietnam \\ ${ }^{4}$ Hanoi University of Public Health, Hanoi, Vietnam \\ ${ }^{5}$ Department of Women's and Children's Health, Karolinska Institutet, Stockholm, Sweden \\ ${ }^{6}$ Department of Global Public Health, Karolinska Institutet, Stockholm, Sweden \\ Email: trchithanh@yahoo.com
}

How to cite this paper: Thanh, T.C., Trinh, P.D., Thanh, N.D., Olson, L. and Larsson, M. (2020) Fundraising Capacity of HIV/AIDS Community-Based Organizations in 3 Years (2017-2019) in Ho Chi Minh City, Vietnam. World Journal of AIDS, 10, 186-194.

https://doi.org/10.4236/wja.2020.103016

Received: August 4, 2020

Accepted: September 15, 2020

Published: September 18, 2020

Copyright $\odot 2020$ by author(s) and Scientific Research Publishing Inc. This work is licensed under the Creative Commons Attribution International License (CC BY 4.0).

http://creativecommons.org/licenses/by/4.0/

\begin{abstract}
HIV/AIDS is still an important public health issue in Vietnam and other developing countries. In Vietnam, Community-based organizations (CBOs) were officially considered as the key partners to approach vulnerable groups at high risks of HIV infection since 2010. Funds for HIV/AIDS prevention and control are facing difficulties due to rapid reduction by international organizations, while domestic funding has not yet met the demand, especially funding for prevention and communication activities. Our study aimed to assess the fundraising capacity of several CBOs in Ho Chi Minh City, Vietnam and analyze the challenges that they are facing now and in future in their work of HIV/AIDS management for community. The 03 typical and representative CBOs (G3VN, Smile and Strong Ladies) were chosen in our cross-sectional descriptive study. The electronic questionnaire was about fundraising reports over 3 years (2017-2019), organization structure (staff, mission, strategies) and the advantages and disadvantages in fundraising. Funds received over the year increased in total, but unstable in each projects. To have more funds, CBOs must invest time and money to have professional staff in fundraising and writing proposals. To meet requirement and survive, some $\mathrm{CBO}$ shifted to social enterprises and faced many difficulties in laws when being treated like profit companies. In Vietnam context, the key challenges which affect the role of funding are including: 1) Legal status; 2) Small scale; 3) Capacity of fundraising (finding calls, writing competence proposals); 4) Fewer funds on HIV/AIDS. In future, we should pay attention in scaling up and building fundraising capacity for $\mathrm{CBO}$ in order to help them
\end{abstract}


in applying for international funds in community projects or even in HIV/AIDS research for $\mathrm{CBOs}$, social enterprises in the context of funds for nation-level phased out of Vietnam.

\section{Keywords}

CBO, HIV/AIDS, Fundraising, Ho Chi Minh City, Vietnam

\section{Background}

HIV/AIDS is still an important public health issue in Vietnam and other developing countries. In 2019, there are more than 250,000 people infected with HIV, of which about 210,000 people known HIV status, and more than 103,000 people died due to HIV/AIDS (as in Figure 1); 100\% of provinces, cities and 98\% of districts have HIV-infected people [1]. In order to end the AIDS pandemic, Vietnam needs to reduce the number of new HIV infections per year to below 1000 cases (currently at 10,000 cases per year) [2].

Civil society organizations and community-based organizations (CBOs) have been considered as an essential element for the global response to the AIDS pandemic [3]. At the local level, CBOs have been engaged in providing services to HIV/AIDS infected and affected people. CBOs are also key partners to governments in responding to HIV/AIDS [4]. In Vietnam, CBOs were officially considered as the key strategy to approach vulnerable groups at high risks of HIV infection since 2010. Remarkably, the HIV risk behaviors are becoming more and more complex, intermingled among intravenous drug user (IDU), sex workers (SW), men who have sex with men (MSM), and transgender women (TG). These organizations help to overcome the stigma and discrimination against people living with HIV or people with risk behaviors of HIV infection in accessing HIV/AIDS care and treatment. Up-to-now, there are $30 \mathrm{CBOs}$, of which $17 \mathrm{CBO}$ officially managed by LIFE Center/Vietnam Union of Science and Technology Associations

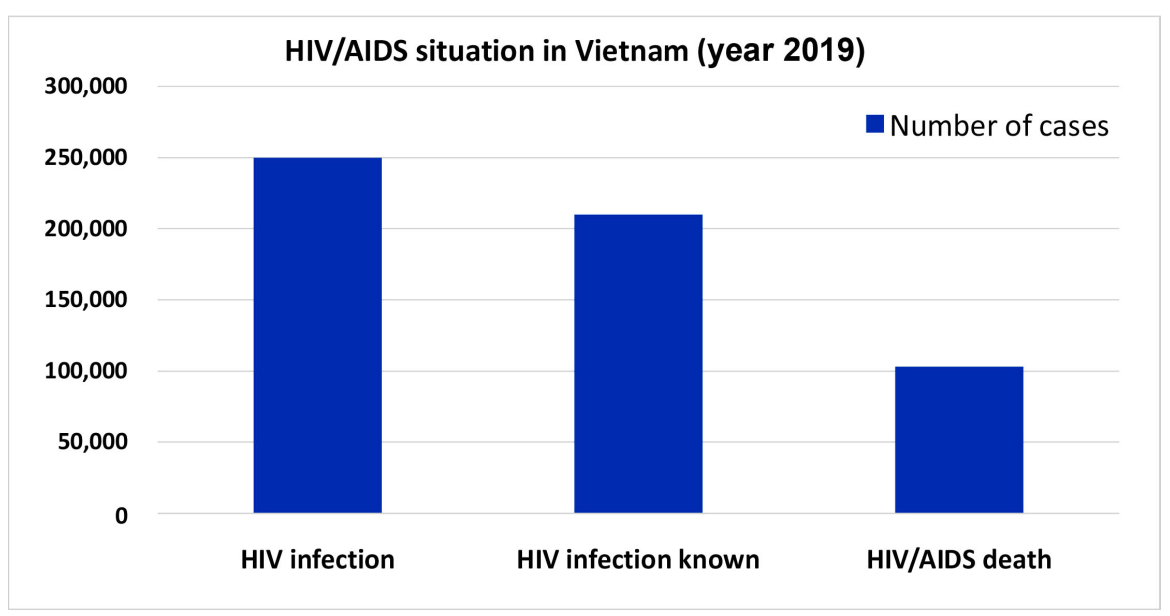

Figure 1. HIV/AIDS situation in Vietnam (year 2019). 
(VUSTA)-Global Fund and 13 small CBOs self-management.

Budget for HIV/AIDS prevention and control services is still very limited. Funds for HIV/AIDS prevention and control are facing difficulties due to rapid reduction by international organizations, while domestic funds have not yet met the demand, especially funds for prevention and communication activities [2].

Our study aimed to assess the fundraising capacity of several CBOs in Ho Chi Minh City, Vietnam and analyze the challenges that they are facing now and in future in their work of HIV/AIDS management for community. This since HCMC has the highest number of $\mathrm{CBOs}$ along with the highest HIV prevalence in Vietnam.

\section{Methods}

The cross sectional descriptive study was done by surveying the successful fundraising within 3 years (2017-2019) of HIV/AIDS CBOs in HCMC, Vietnam.

There are 17 official CBOs classified by 3 groups (years of working; scale; and their performance). Within 3 groups, the 03 typical and representative CBOs were chosen randomly. The electronic questionnaire was about the organization structure (number of core staff, CBO mission, current and future strategies), the funds received within 3 years (projects, funders, amount of budget).

The 03 in-depth interviews with $\mathrm{CBO}$ managers on advantages and disadvantages in fundraising were done.

Data collected by a designed electronic questionnaire (descriptive quantitative data) were analyzed by chart and data collected by in-depth interviews (qualitative data) were analyzed by interpreting key informants and ideas.

This study was not involved HIV patients so the ethical certificate was not applied. The survey was done on December 2019.

\section{Results}

\subsection{Brief Information of 03 Representative CBOs Participated in the Survey}

G3VN (code CBO-1, 15 core staff and with professional fundraiser staff) is one of the strong community support organizations in Vietnam established in 2011, specializing in providing preventive health care services for HIV/STIs, mental health, and sustainable livelihoods for disadvantaged communities in Vietnam. G3VN stipulates that at least 10 community initiatives are designed by G3VN itself and send to local and international donors to raise funds. Community initiatives will be implemented specifically for MSM, TG, MSW, and LGBT youth who use drugs and people with HIV.

Smile (code CBO-2, 20 core staff and without professional fundraiser staff) is a self-help group established in December 2006 with the aim of improving the quality of life for PLHIV and reducing the risk of HIV transmission among high-risk groups such as injecting drug users. Since the end of 2016, the group has been supported by USAID-CLink-Southern project to transform into Smile Social Enterprises. Main activities for the community as following: 
- Coordinating with sponsors on the occasion of Tet gifts, visiting and giving gifts to OPC (Out-patient-clinic) children in difficult circumstances.

- Develop and link self-help, voluntary groups, religious and charitable organizations in HIV/AIDS field.

- Prevention of HIV transmission among injecting drug users in Ho Chi Minh City and support them to access harm reduction services and methadone substitution therapy.

- Care and support for effective adherence to ARV treatment.

Strong Ladies (code CBO-3, 18 core staff and with professional fundraiser staff) was established on October 20, 2013 as a self-reliant group of independent transgender women. In December 2016, Strong Ladies officially became a community-based organization (CBO) with technical support from the Center for Quality of Life (LIFE). Strong Ladies is a civil society organization that develops sustainably for the sake of health care; advocating for rights and policies for the LGBTI + community through capacity building activities and effective resources connecting to the message "STRONG AND MORE" and the mission "Taking care of health and promoting equal rights for vulnerable communities" through domestic and foreign resources.

\subsection{Fundraising Report over 03 Years (2017-2019)}

The 03 CBOs in our study received small funds (less than $\$ 50,000 /$ project). Actually, they received sub-contracts from international NGOs in Vietnam through the call for short-term project proposals, such as Trans-Voice, $\mathrm{K}=\mathrm{K}$; and or appointed annual contract through VUSTA such as Global Fund to Fight HIV/AIDS project, USAID Enhanced Community HIV Link-Southern project.

Funds received over the year increased in total, but unstable in each projects, especially annual ones like Global Fund for CBO-2 (\$39,480/in 2017, \$24,706/in 2018, \$22,781/in 2019) as in Figure 2 and for details in Table 1.

\subsection{The HIV/AIDS CBO Advantages and Disadvantages in Fundraising}

\section{*Advantages}

CBOs are able to do HIV/AIDS community support or intervention projects

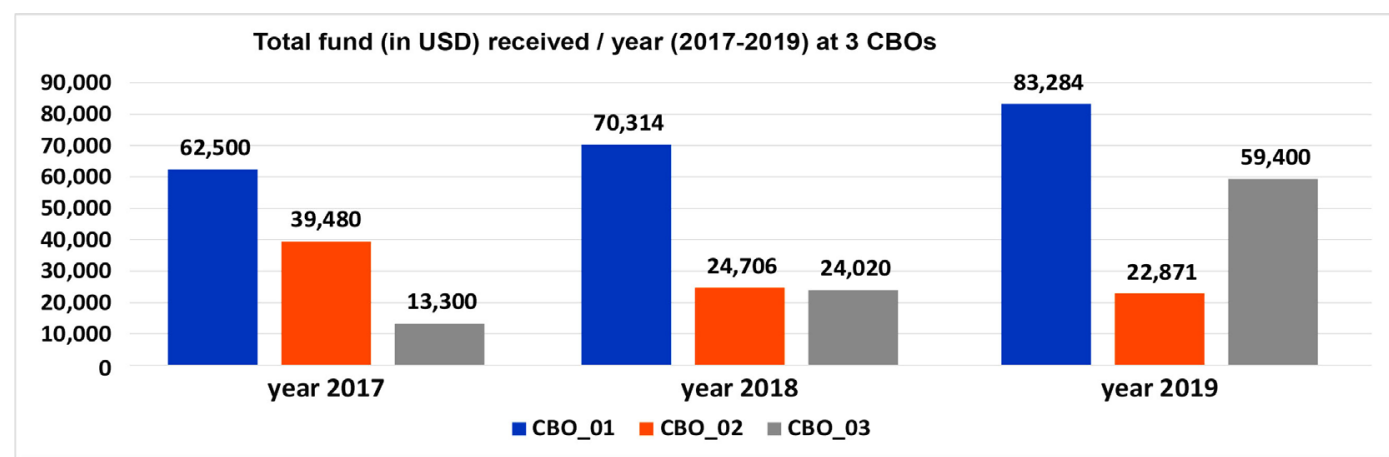

Figure 2. Total fund received/year at $3 \mathrm{CBO}$ in our survey. 
Table 1. Fundraising reports in 3 years.

\begin{tabular}{|c|c|c|}
\hline & ${ }^{\star} \mathrm{CBO}-1$ Funds received & \\
\hline \multirow[t]{4}{*}{ In 2017} & Global Fund to Fight HIV/AIDS Project & $\$ 20,000$ \\
\hline & USAID Enhanced Community HIV Link-Southern Project & $\$ 22,500$ \\
\hline & $5 \%$ Initiative & $\$ 10,000$ \\
\hline & USAID Healthy Markets & $\$ 10,000$ \\
\hline \multirow[t]{9}{*}{ In 2018} & Global Fund to Fight HIV/AIDS Project & $\$ 22,684$ \\
\hline & USAID Enhanced Community HIV Link-Southern Project & $\$ 21,500$ \\
\hline & Undetectable $=$ Untransmittable Project & $\$ 1000$ \\
\hline & $5 \%$ Initiative & $\$ 10,000$ \\
\hline & Trans-Voice Project & $\$ 1500$ \\
\hline & USAID Healthy Markets & $\$ 3630$ \\
\hline & Consultancies & \\
\hline & - Client counseling and referral to STIs services & $\$ 9,000$ \\
\hline & - Facilitation of focus group discussions study & $\$ 1000$ \\
\hline \multirow[t]{5}{*}{ In 2019} & Global Fund to Fight HIV/AIDS Project & $\$ 22,684$ \\
\hline & USAID Enhanced Community HIV Link-Southern Project & $\$ 25,600$ \\
\hline & $5 \%$ Initiative & $\$ 10,000$ \\
\hline & Trans-Sextion Project & $\$ 25,000$ \\
\hline & * CBO-2 Funds received & \\
\hline In 2017 & Global Fund to Fight HIV/AIDS Project & $\$ 39,480$ \\
\hline In 2018 & Global Fund to Fight HIV/AIDS Project & $\$ 24,706$ \\
\hline \multirow[t]{2}{*}{ In 2019} & Global Fund to Fight HIV/AIDS Project & $\$ 22,871$ \\
\hline & ${ }^{*} \mathrm{CBO}-3$ Funds received & \\
\hline \multirow[t]{2}{*}{ In 2017} & Global Fund to Fight HIV/AIDS Project & $\$ 9300$ \\
\hline & USAID Enhanced Community HIV Link-Southern Project & $\$ 4000$ \\
\hline \multirow[t]{4}{*}{ In 2018} & Global Fund for HIV/AIDS Prevention & $\$ 16,600$ \\
\hline & USAID Enhanced Community HIV Link-Southern Project & $\$ 5100$ \\
\hline & PITCH-sponsored transgender women's health care initiative & $\$ 1400$ \\
\hline & CDC-Project $\mathrm{K}=\mathrm{K}$ initiative & $\$ 920$ \\
\hline \multirow[t]{5}{*}{ In 2019} & Global Fund for HIV/AIDS Prevention & $\$ 19,400$ \\
\hline & USAID-Enhanced Community HIV Link-Southern Project & $\$ 3000$ \\
\hline & Australian Consulate General_"For You to Believe" for TG & $\$ 2000$ \\
\hline & CDC-Project $\mathrm{K}=\mathrm{K}$ initiative & $\$ 3000$ \\
\hline & Umbrella Fund-Project "Health care for transgender women" & $\$ 32,000$ \\
\hline
\end{tabular}

when they themselves are people in those vulnerable communities (IDU, SW, MSM, TG). The feasibility of any community project depends mostly on the number of target population that $\mathrm{CBO}$ s could approach and support. 
CBO-2 response: "Our group members have been working in HIVIAIDS for a long time so they have a lot of experience. And they have the same situations, so it is easy for them to have mutual assistance. Every member understands his role, position and duties when doing community projects".

In the context of the big funds phasing out of Vietnam, the small funds are still available and suitable for CBOs with small projects in a short-term on HIV education and communication, but in future they would mainly focus on treatment programs.

CBO-3 response: "Funding resources for HIV remain in current and future contexts. However, such resources are shifting more on treatment programs, less on communication programs".

CBOs receive fruitful supports from government, local authorities in HIV/AIDS works. This is the strong point to assure the project feasibility to funders.

CBO-2 response: "There is a connection to community-based activities with supports from local authorities and other organizations as well as health facilities".

In Vietnam, the social enterprise is the new form of business that CBOs try to transform in order to have legal status and official stamp. With legal authority, they could apply directly for international funds and receive money legally.

CBO-1 response: “ $G 3 V N$ is a community-based organization ( $C B O)$ operating from 2011 to present in the field of HIVISTI prevention interventions. In 2016, G3VN transformed itself into a social enterprise with its own legal status and stamp".

\section{*Disadvantages}

CBOs without strategies of seeking extra sources or projects do not invest in fundraising staff or department. They found that they were not capable of receiving other funds.

CBO-2 response: "Most of our activities are funded by the VUTSA-Project on HIVIAIDS Prevention and Control Project through the Life Center, while other sources have not been able to access it yet. In addition, we are not good at English so we could not write the proposal in English".

CBOs with active team members invest in fundraising staff or hire out-source consultant. They do understand the competence in applying for funds in this period.

CBO-3 response: "The resources of HIV funds have decreased comparing to the past, but the increasing number of $C B O$ s has led to more competition when writing project proposals. Proposals must be truly creative and practicaP'.

CBOs transformed to social enterprise have to face lawful disadvantages when being treated the same as a profit ones.

CBO-1 response: "There is no tax exemption mechanism for us when working on HIV with supportive funds. The legal framework is unclear for purely social enterprises operating not for profit. And there is no network or specialized unit to support information for Social Enterprises in fundraising". 


\section{Discussion}

HIV/AIDS management in Vietnam has mainly been funded by international funds. The international funds declined by almost 13\% between 2014 and 2015 and the Vietnamese Government is using national funds to compensate and social health insurance is being applied to HIV patients [5]. In the context of the international funds phasing out, HIV/AIDS national program is facing many difficulties in both policy and implementation levels [3]. The concept of community involvement in improving health outcomes is not a new one. It has its roots in the action that communities have always taken to protect and support their members. Since 2017, there have been some small funds left for handover period. With new strategies, these small funds were appointed to CBOs, but gradually decreased over the years and greater competition for CBOs. In our survey, the total amount funds in a year were not higher than 100,000 USD for the most active CBO-1 in 2019.

In Vietnam, official CBO organization structure is similar to standard one including at least 5 different staff (as in Figure 3). In order to apply for funds to do community projects, CBO must have professional staff or hired consultants in having initiative ideas, high quality proposals. The extra staff depends on CBO priorities or strategies. CBO-1 and CBO-3 mainly use the extra project funds for maintaining their organizations, meanwhile CBO-2 simply uses the appointed project funds from VUSTA/Global Fund. So, there is no extra staff for fundraising at $\mathrm{CBO}-2$ and it is the crucial disadvantage for $\mathrm{CBO}-2$ to develop in future. CBO-1 and CBO-3 are found more active in applying proposals for funds than CBO-2 when they have professional staff to follow-up the call for proposals, news on funding and to prepare proposals in English for international sources. The total amount funds were received and increased over the years at CBO-1 and $\mathrm{CBO}-2$, but decreased at $\mathrm{CBO}-3$, it is comprehensible.

With the fund reduction, $\mathrm{CBO}$ have a tendency of transforming themselves

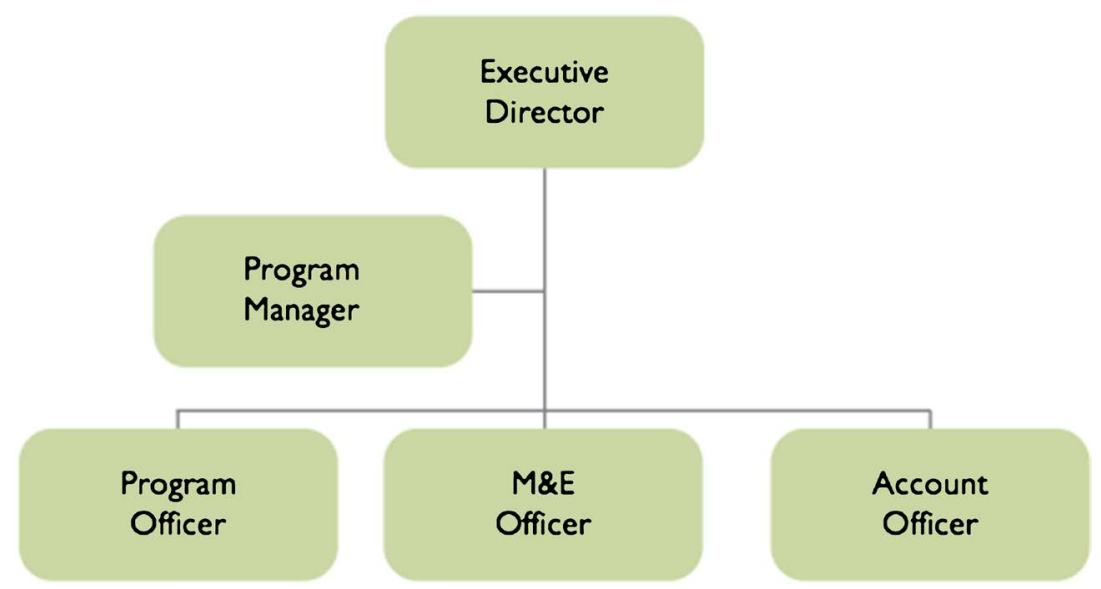

Figure 3. Organizational chart of a small CBO in Taraba State (https://www.msh.org/sites/default/files/building_success_vol2_strengthening_the_long-t erm_capacity_of_community-based_organizations.pdf). 
to social enterprises. According to the conference on September 29 in Ho Chi Minh City, 6 out of 31 CBOs in the south have turned into social enterprises. G3VN (CBO-1) for the gay community changed itself to a social enterprise by running Galant General Clinic specializing in diagnosing HIV infection, treatment of sexually-transmitted diseases. It also pledged to set aside $51 \%$ of its profits for supporting the gay community [6]. Being a social enterprise, CBO-1 and CBO-2 are being treated like a profit enterprise in law, because there is no exception for this kind of business in Vietnam now. This is the most disadvantage for CBOs when receiving sponsored fund from international funders. The received funds are considered as income with paying for tax and valued added tax as well. For CBOs without legal status and seal like $\mathrm{CBO}-3$, they must receive funds from other organizations as sub-contract or be hired as short-term staff only.

Currently, there are many domestic funds from companies or sponsors mainly for vulnerable groups like handicapped or old or poor or immigrated people. The social stigma and discrimination on HIV/AIDS still exists, so PLWH receive supports as the poor people. In future, we should keep on increasing society awareness that helping PLWH is crucial to rule out HIV/AIDS pandemic. With lower social stigma and discrimination, we could allocate the domestic funding for PLWH.

\section{Conclusion}

In Vietnam context, the key challenges which affect the role of funding are including: 1) Legal status; 2) Small scale; 3) Capacity of fundraising (finding calls, writing competence proposals); 4) Fewer funds on HIV/AIDS. We should pay attention in scaling up and building fundraising capacity for CBOs in order to help them in applying for international funds in community projects or even in HIV/AIDS research for CBOs, social enterprises in the context of funds for nation-level phased out of Vietnam.

\section{Acknowledgements}

We would like to thank Mr. Pham Hong Son (G3VN Social Enterprise), Mr. Trang Van Toan (Strong Ladies CBO, and Mrs. Nguyen Thi Nhieu Kim (Nu Cuoi-Smile Social Enterprise) for joining our study to provide fundraising data and to share precious opinions/comments on our manuscript.

\section{Conflicts of Interest}

The authors declare no conflicts of interest regarding the publication of this paper.

\section{References}

[1] Vietnam Government Report on Ending HIV/AIDS Pandemic in 2030. http://baochinhphu.vn/Chinh-sach-moi/Cham-dut-dich-benh-AIDS-vao-nam-2030 
1391080.vgp

[2] Vietnam Government Report on HIV/AIDS Prevention and Control. http://tuyengiao.vn/van-hoa-xa-hoi/xa-hoi/phong-chong-hivaids-o-viet-nam-mot-s o-ket-qua-kha-quan-125638

[3] Schwartlander, B., Stover, J., Hallet, T., Atun, R., Avila, C., Gouws, E. and Padian, N. (2011) Towards an Improved Investment Approach for an Effective Response to HIV/AIDS. The Lancet, 377, 1-11. https://doi.org/10.1016/S0140-6736(11)60702-2

[4] UNAIDS (2005) Report on a Joint UNAIDS and Civil Society Planning Meeting on UNGASS 2006 Preparation. Strengthening the Response to HIV and AIDS at Local, Country and Global Level: The Role and Opportunities for Civil Society in Tracking Progress toward UNGASS Target. Geneva.

https://data.unaids.org/publications/irc-pub06/recife_report_2005_en.pdf

[5] Tran, C.T., Ngo, V.A., Pham, T.V., Larsson, M. and Do, D.C. (2017) Increasing HIV-Infected Patients' Readiness for Social Health Insurance to Cover Partial Antiretroviral Therapy Fee in Vietnam. Current Research HIV 2017: CRHA-112.

[6] VOV News on HIV/AIDS Conference on CBOs in Hochiminh City. https://m-english.vov.vn/society/communitybased-organisations-tend-to-turn-intosocial-enterprises-359498.vov 